\title{
Agents of Ishq and Contemporary Discourses on Sex and Sex-Education in India
}

\author{
Anomitra Biswas \\ Academic Fellow, Balvant Parekh Centre for General Semantics and \\ Other Human Sciences, Baroda, India \\ biswas.anomitra@gmail.com \\ Tonisha Guin \\ Academic Fellow, Balvant Parekh Centre for General Semantics and \\ Other Human Sciences, Baroda, India \\ guin.tonisha@gmail.com
}

\begin{abstract}
This paper examines Agents of Ishq, an online site/project seeking to create a space for the public discourse of sex and sexuality in India, with particular attention to a single music video that is part of the project. The content produced by the project is informed by idioms of Bollywood films and film-music. The paper draws on the notion of popular culture to see how meanings are encoded within the video productions and explores the politics of representation of these audio-visual and textual resources. It also briefly examines the effect that being hosted on a digital platform, freely accessible at any time and from any location, (rather than as part of traditional and broadcast media) has on the content produced by Agents of Ishq. It examines the need for the proliferation of pedagogical resources of this kind and, at the same time, draws attention to the ways in which they need to be critically problematized in terms of the cultural hegemonies they may run the risk of reinforcing.
\end{abstract}

\section{Keywords}

digital resources - popular culture - sex education - India 


\section{Introduction}

Walter Mignolo argues for the need to destabilise hegemonic, hierarchised systems of knowledge that perpetuate select processes of otherising (Mignolo 2019). Local and locally-sustained hegemonic structures often borrow from and stabilise themselves in relation to knowledge systems rooted in the Global North. Problematising the heirarchised North-to-South power/knowledge structures therefore disrupts these as well. The discourses on (heteronormative) norms of courtship, romance, sexual relationship and sex-education in the mainstream social imaginary in India - both within the juridico-legal state machinery and in the more aesthetically worded popular cultural productions like Bollywood films - is an arguably good illustration of this. ${ }^{1}$

However, the discourse on sex/sexuality/sex-ed is no more homogeneous than the range of communities, cultures, sources of media-pictorial, audiovisual, oral, literary - that participate in and produce it. There is a need to examine the ways in which the digital networks focussing on sex/gender/ sexuality create and sustain themselves across national borders, and also the ways in which localized adaptations and transformations of cultural productions take place. Public discussions around sexuality are thought of as not conforming to commonly-held norms of civility and appropriate behavior. As such, even government-mandated cultural texts and campaigns around reproductive health, sexual practices, safe sex, and gendered interactions have faced resistance and opposition in mainstream Indian culture. The generally favourable reception of transformative work (especially with easily-identifiable borrowings from the film industries) is also affected by this attitude when it comes to transformative media explicitly addressing sexual relations (Lawrence Liang, 2011).

India's official policy regarding sex-education for adolescents-as distinct from that offered to adults or about HIV/AIDS - may be largely in line with norms in the Global North, but implementation is scattered at best and largely disregarded. Arguably, its adherence to those norms may have negatively affected acceptance, since the legislative bodies of several states argued that sex-education was a western (or Global North) construct, inimical to Indian values, and that it would corrupt Indian youth. In 2007, the Ministry of Human Resource Development formulated and promoted a sex-education curriculum for the country. Opposition was immediate and has been sustained. Several

1 Bollywood, and other regional entertainment industries, depict sexual and romantic practices across a range of geographical and socio-economic locations that are variously treated within the narrative as transgressive or acceptable, often with the same act being accepted and transgressive in different narratives, or in different locations in a single narrative. 
states formally banned sex-education, ${ }^{2}$ while idealogues from or influencing conservative parties further suggested that sex-education should result in the teacher being jailed. Even states which did not denounce it in such a determined fashion have largely let sex-education fall by the wayside. The New Education Policy unveiled in April 2020 advocates for sex-education in secondary schools, but this suggestion - though not yet implemented — has already met opposition from entrenched right-wing bodies. In its way, this is a fascinating portrayal of the resistance to hierarchically-privileged knowledge systems: not through a refutation of information made available, but through resistance of its place in Indian society.

In light of this resistance, any discussion of sex in the public sphere primarily occurs in relation to sexual violence or the field of gynaecology/obstetrics: in effect, sex is predominantly only discussed when criminalised, pathologised, or both. Private schools are free to include sex-education in their curriculum, but informal surveys conducted in Kolkata, Hyderabad and Vadodara shows that few do so in practice. Biology lessons for Grades XI and XII may include brief discussions about safe sex appended to lessons regarding human anatomy and physiology: if attention is paid to the socio-cultural or emotional aspects of sex, it is only to urge abstinence. ${ }^{3}$

This abstinent attitude even applies to discussions about the non-marital sexual behaviour of adults (Bahukhandi 2017). This restrictive stance towards sex, and an accompanying normalisation of sexual violence, has resulted in frank conversation about sexual desire and activity being cast in an illicit light,

2 The Maharashtra state government banned sex-education in schools in March 2007, following protests by MLA s from both the ruling party and opposition; Shiv Sena MLA Rajendra Patni opined that sex-education was capable of "spoiling the younger generation" (The Indian Express, 31.03.2007). In April 2007, Karnataka refused to implement sex-education, with Primary and Secondary Education Minister Basavaraj Horatti citing strong objections by teachers who feared that students might get "sexually provoked by [the] illustrations" included in the pamphlets and handbooks and further that sex-education might "make HIV/AIDS an industry at the cost of children" (OneIndia, 18.04.2007). In May 2007, Rajasthan Chief Minister Vasundhara Raje called sex-education "adverse to Indian culture", while the state's Education Minister found it "disgraceful and capable of corrupting the minds of the young" (The Indian Express, 03.05.2007). In Uttar Pradesh, teachers threatened to burn the books on sex-education provided by the CBSE board unless they were withdrawn, with Om Prakash Sharma, chief of the secondary schools teachers' association, saying that the texts were "bound to not only poison young minds but also become a source of embarrassment for teachers" (Hindustan Times, 09.07.2007).

3 In April 2021 Agents of Ishq posted results from a survey of the things their readers were told in, and in lieu of, sex-education classes ("agents of ishq", Instagram, 17.04.2021). Neither the omissions nor the information made available is startling to those who have been subjected to what most Indian schools consider adequate sex-education. 
as equally inimical to social values. In some situations, violence is perceived as a justifiable response to consensual sexual intimacy; one may look to cases of honor-killing and associated sexual violence. While the stigma associated with partaking in and especially initiating conversations about sex might vary in different regions and communities, it lingers regardless: diffuse or concentrated. The lacuna left by institutional refusal and familial resistance about engaging in sexual conversation is filled by depictions in popular culture and pornography, such that "[p] ornography hugely dominates people's knowledge about sex." (Krishna 2020). One must note that pornography is banned in India, though not inaccessible. (Chandani 2020).

The position occupied by the internet in regards to popular culture-especially online spaces like YouTube and the recently-banned Tiktok-is interesting and as with many interesting things, ambiguous. Internet access-even though it is now significantly more pervasive in India due to the smartphone revolution-remains a matter of privilege, and internet-fluency a prestige marker of sorts. Despite inequalities of access, it is also one of the greatest equalisers in modern capitalist democracies, especially as a tool for sharing cultural productions. Further, the sharing and creative networks of the internet-even with a significant portion of the latter made inaccessible through paywalls, geolocking and lack of technical knowhow-make it one of the greatest tools available for creative minds, albeit one that is unevenly distributed and wildly heterogenous in both form and content. In countries like India, where a conservative society and constrictive government often collude to censor information and censure those who disseminate it, the internet therefore becomes an irreplaceable though manipulable resource (в вс News, 03.03.2021). While adolescents certainly learn about sex in mutual discussion and experimentation, one may assume that a significant portion of the knowledge disseminated is rooted in media depictions, which therefore gain a perhaps outsized importance. This may go some way in explaining the barrage of criticism levelled at films like Kabir Singh (2019) or Inkaar [refusal] (2013) that normalise and glorify misogynistic behaviour, sexual molestation and violence, dubious consent, gaslighting, and domestic abuse.

Insofar as an overarching popular culture may be identified in India, a significant part of it is linked to cultural productions rooted in the Mumbai film industry, or Bollywood: including movies, music (and music videos) and, more recently, online media productions. Distinctions about prestige and popular films linger despite the characteristic differences between arthouse and commercial film having largely disappeared in favour of a chaotic heterogeneity. Depictions of consensual sex and conversations about sexual relations have existed in the Indian entertainment industries for decades, especially 
in parallel cinema and increasingly in commercial releases. However, these depictions - already slim pickings - cannot assume the entire burden of creating either a space or the tools required to engage in conversations about sex. Consequently, there remains a severe lacuna in the public sphere insofar as easily-accessible, pedagogical material about healthy and consensual romantic and sexual desire and acts is concerned: the situation, already bad for heteronormative, heterosexual individuals, is positively dire for those who fail or refuse to conform. Of late, several Indian feminist and queer groups and individuals have attempted to create these spaces and tools, but much of the conversation has still been dominated by concepts of rape culture: while necessary, it continues to make the discourse surrounding sexual desire, deportment and acts center violence. In light of the occurance and reportage of sexual violence in the last several years- the class-caste aspects of which are typically ignored - one may say that this has grown rather than lessened.

Hall (1981) discusses popular culture as being constituted through the interaction of tendencies towards resistance and containment, such that it is neither exclusively pablum fed to the masses, as Adorno and Horkheimer decry, nor a perfect instantiation of mass resistance $\left(23^{2-233)}\right.$. Rather, it incorporates both, often simultaneously. Further, transformative work emerging from corporatised popular culture may serve as a secondary site of containmentresistance where topics only hinted at or entirely elided in the former finds more explicit depiction/discussion.

This paper takes a constructionist approach and posits that all ideas are socially constructed and discursively produced; any representation is not simply reflective of a pre-existent idea: it reiterates and constitutes it (Hall 1997: 15). It looks at the discursive construction of love, sex and sexuality on an online platform called Agents of Ish $q^{4}$ [Agents of Love], in particular a musical video about the importance of consent in sexual acts. In so doing, it primarily reads and analyses the linguistic signs employed in these multi-media texts and locates them in relation to some of the extra-linguistic components of the video. Examining the ways in which these texts produce meaning allows it to question the claims the website puts forth, and see how, in the very acts that seek to promote intelligibility and accessibility, the website and, particularly, the video, create new pockets of esotericism and ambivalence.

Agents of Ishq emphasises its standing as an Indian website discussing Indian attitudes and issues about love, sex and desire; in so doing, it reiterates and constitutes the desirous/desirable Indian as both its subject and object of

4 Ishq (عشتق) is an Arabic word in common use in Urdu-Hindi, primarily used to denote a romantic and (often) sexual attachment. 
discourse. If Agents of Ishq is read as pedagogical, it is so in Michel Foucault's understanding of pedagogy in which techniques of pedagogy are a part of a body of disciplinary power relations that act on an individual to interpellate them into a (docile) subject. Disciplinary power is an integral part of Foucault's understanding of governmentality in modern capitalist democracies (Foucault 1980: 133).

This paper dwells upon Agents of Ishq's projection of its Indianness, but without conflating the nation with the state. Rather, it is interested in reading the site as a microcapillary of power-relations around sex/gender/sexuality, in line with Foucault's concept of governmentality.

There is both a "downward" and "upward" link between the state and the micropolitics of everyday life (Foucault 2007: 94-95), which, we may add, constitutes the sphere of the national. Thus, governmentality is a way of acting upon peoples' conduct that is not restricted to the state, though it may refer in the final instance to state action - not because the state is supreme but that in formulating its policies, it takes account of and coordinates between the other instances [...] One mode of governing acts directly upon peoples' conduct, prescribing some forms of behaviour and prohibiting others, while the other induces people to act upon themselves and is more properly a "conduct of conducts" (DAS 2019: 30-31).

Das discusses the way in which health education, especially in the context of sexual health, has been implemented in a top-down way wherein the "facts" of disease transmission are conveyed by the educators without examination of the structural causes-financial and gender inequalities, among others-that affect unequal access. Further, in a pattern evocative of the "banking model," true knowledge is assumed as resting with the educator, while learners have no or false information. The situation with sex-education in India is not dissimilar, with state health and education ministries presumed to be in charge of the truth of the matter, and students only capable of sexual acts if taught about sex/sexuality/sexual health by authoritative individuals and groups. Sexual activity is predicated upon sexual education. Das' criticism about AIDS pedagogy applies to Indian sex-education insofar as this is an untenable assumption, because sexual behaviour is "driven not by knowledge or reason alone, but equally by impulses that are not subject to rational calculation" (Das 2019: 25). Das deprecates the top-down approach to sexual health education, as it ignores ground reality and valorises individual knowledge. Of course, in case of sex-education in schools - unlike the AIDs pedagogy with which Das is concerned - the valorisation may more correctly be said 
to centre around ignorance rather than knowledge: there appears to be an assumption that sex-education will cause students to engage in sexual activity, while ignorance will result in chastity.

Agents of Ishq's work - whether in stand-alone videos or art installations, in hosting queer anecdata, in their advice column, or in lists of words for kissing in Indian languages - strives not simply to clothe what are thought of as Western/Global North views in Indian raiment, but to discuss sex and desire as universal and also native. This can also be seen in the Love Latika (Paromita Vohra, 2019) art installation and in a video, "Love in the Garden of Consent," which uses Bollywood tropes and tunes to conduct a discussion about sex.

This paper does not seek or record audience/reader responses to the work done by Agents of Ishq, instead limiting itself to the language used in textual and audio-visual posts, as captions and subtitles. However, the site/project may itself be read as a private response or cluster of responses participating in the state-governed but heterogenous discourse about romantic love, sex and sexuality in India.

\section{Conceptual Framings Regarding Media, Culture and Pedagogy}

As an academic discipline, pedagogy is the study of the ways in which skills and knowledge are conveyed in an educational context, as well as of the interactions that occur during the learning process. The aims of pedagogy may range from the constraints of vocational education - which involves the acquisition of particular skills - to the broader realms of liberal education, which often aspires to the development of the human potential of learners. As such, pedagogy always has an ideological ${ }^{5}$ component that relates to perspectives about learners, teachers, and the learner-teacher relationship. For instance, Global North mainstream pedagogy views the teacher as the knowledge-holder who

5 The most long-lasting and authoritative Marxist account of ideology in the context of cultural studies has come from the writings of Gramsci that became especially influential within cultural studies during the late 1970s. For Gramsci ideology is grasped as ideas, meanings and practices which, while they purport to be universal truths, are maps of meaning that support the power of particular social classes. Here, ideology is not separate from the practical activities of life but provides people with rules of practical conduct and moral behaviour rooted in dayto-day conditions. Ideology is understood to be both lived experience and a body of systematic ideas whose role is to organize and bind together a bloc of diverse social elements, to act as social cement, in the formation of hegemonic and counterhegemonic blocs. Though ideology can take the form of a coherent set of ideas it more often appears as the fragmented meanings of common sense inherent in a variety of representations. Within this paradigm common sense and popular culture become the crucial sites of ideological conflict. (Barker 2004: 97). 
imparts the same to a learner, in what Paulo Freire dubs the "banking model" (Freire 1970: 58) but newer theories of pedagogy, in the same spaces increasingly assign a more agentive role to learners while viewing teachers as facilitating the process.

In his work on governmentality, Foucault discusses the disciplinary techniques, the "new micro-physics of power" that spread out across institutional sites from prisons and army barracks to hospitals and workshops, and of course schools in seventeenth century Europe. (Foucault 2000: 45) The aim of these techniques was to inculcate habits of obedience and aptitude, to turn people teachable or docile. For Foucault, therefore, pedagogy is one of a number of disciplinary mechanisms that comprise the productive use of power. Foucault, Michel. (1977) Pedagogy as a mechanism of productive power increases the teachability of students, who become simultaneously more easily controlled and empowered through the processes of pedagogy, insofar as it enables them to become more - and more correctly - productive. For modern subjects acting on themselves - and simultaneously being acted on by social institutional power relations through pedagogical practices-the pedagogical domain extends far beyond conventional understandings of academic institutions or pupils.

The Foucauldian construction of pedagogy is not far removed from two seminal works on pedagogy: Louis Althusser and Paulo Freire's commentaries on education. In Pedagogy of the Oppressed, Freire distinguishes the aforementioned "banking method" from "problem-posing," a dialogic pedagogy that encourages critical thinking instead of rote learning. In the latter, learners are encouraged to critically engage with the world and to perceive it as not static but instead in process. Pedagogy is only valid when learners are taught to "learn the reason-for [...] of the object or the content" (Freire 1994: 68). Freire thus doubly links pedagogy to power relations, such that the banking model reinforces and the problem-posing model critiques social hierarchies. Althusser's (1971) critique of the education system is similar to Freire's, insofar as the role of ideology is concerned. Althusser views schools as ideological apparatuses of the state, which convey the ruling ideology to students, and ensure the maintenance of domination through various means, including a hierarchisation of forms of knowledge and/or skills. Such hierarchisation ensures the perpetuation of existing social conditions and implicates pedagogy in the social domination by the bourgeoisie. Governmentality does not rely on a centralised state effort alone:

it was not exercised by the state alone or its institutions: the state was simply the coordinator and facilitator of networks of power relationships 
arising at various levels, a function that varied historically in its centripetal strength and effectivity (DAS 2019: 20).

Freire and Althusser both view pedagogy as mainly serving the interests of the dominant and oppressive sections of society. However, both believe that alternate pedagogy is essential to the creation of critical consciousness: while Freire trusts in the problem-posing method, Althusser looks to teachers who dismantle the ideological system from within. Freire's theory of the mechanisms of subject formation through pedagogy assumes that freedom and creativity are innately human. Althusser's account echoes the Lacanian conception of mis/ recognition promulgated in the "Mirror Stage" essay. Despite these and other differences, both construct subject formation as the goal of pedagogy.

Althusser considers the chief function of the educational ideological apparatus to be the creation of compliant subjects; learners are induced to misrecognise their relation to social reality, interpellated and simultaneously constituted as free subjects and subjected beings. Following Althusser, we are pedagogically constituted as subjects through being addressed and responding to that address: this is the process of interpellation through hailing. In the absence of state support and governmental curricula, or indeed an explicit statement by Agents of Ishq about being pedagogical, it is this that characterises the site/project as pedagogical, insofar as it interpellates readers through addressing them.

Foucault's stance on pedagogy as governmental is distinct from those of Freire (with a pre-formed subject who may be "fully human" through critical pedagogy instead of the banking-model) and Althusser (for whom pedagogy can convey ideology, or reflective knowledge). Instead of the emphasis on the mind, and consequently, mind-over-body that Freire and Althusser maintain, Foucault emphasises the role of the body and foregrounds the need

to move beyond the mind/body dichotomy, to suggest how the objective of pedagogy is not merely to induce learners to think in certain ways but equally to induce in them appropriate modes of embodiment. [Thus], "discipline" refers to both a branch of knowledge and a training of the body. By knowledge, again, Foucault refers to that which is communicated to the learners as well as that which needs to be produced in order to develop more effective strategies of teaching - a meticulous knowledge of the students' abilities and aptitudes, their progress in the educational system and their behaviour patterns, as well as theories of education (DAS 2019: 28-29). 
Drawing on the above, pedagogy related to sex/gender/sexuality is not limited to initiatives by the states even as the state necessarily remains the dominant actor despite its in/action, because of its control of both public health and education. Governmentality is constituted by numerous relations of power that may not be connected to or in alignment with the views of the state. This paper reads Agents of Ishq as a microcapillary of such power-relations and, as such, an important site in understanding the taxonomies of Indian sex/gender/sexualities, and of reactions to pedagogy in this matter. These reactions cannot be simply mapped onto absolute compliance or resistance: most individuals operate between these extremes, and there is accordingly a vast heterogeneity of sexual practice that often goes unmapped.

By the 1930 one finds, in England and elsewhere, popular culture doled out by capitalists to the masses, feeding them an abbreviated and sanitised version of their own ways of life (Hall 1981: 231). In "The Culture Industry: Enlightenment as Mass Deception" Adorno and Horkheimer liken the entertainment industries to factories churning out standardised cultural texts the consumption of which renders the populace docile: a perspective with which Hall does not entirely agree (Adorno and Horkheimer 1947). Rather, Hall ascribes to a notion of containment and resistance, whereby the populace both accepts and resists its depiction in mainstream media. Working-class and other counterculture and subculture media productions become niche-with limited reach — or beholden to rich individuals or groups with aligned tastes and ideologies, who can serve as sponsors: marginalised in one way or another, compared to the dominance of mainstream cultures. The centralisation of media houses has only grown more obvious and dire, with six media conglomerates owning almost the entire American culture industry (Louise 2020). The situation in India is somewhat more diffuse, but even so a few media powerhouses-for instance Ananda or Zee or Star-occupy a sizable chunk in all regional markets, and even branching into new media. Further, there are tie-ups with American media houses - for instance the Disney+ collaboration with HotStar - that implicate Indian media in the network of the American and international culture industry.

New media encompasses various forms of digital media that may be partially or wholly digitally produced and are digitally distributed and consumed: this includes video games, podcasts, media websites and отт media platforms, among others. New media is, therefore, very much constitutive of the media conglomerates previously mentioned, since these conglomerates own any number of video games, отт media platforms, and websites. The corporatisation of new media is not only prolific, but also deeply insidious. However, new media can be hosted, viewed, and shared for minimal costs or even without 
an upfront payment by the creator/host. The lower production costs enable smaller media companies, groups, or even individuals to create media with slicker aesthetics and higher production-values than possible under the auspices of broadcast media. Further, in India отт media platforms are subject to fewer, and less censorious restrictions than broadcast media, though this is likely to change in the near future (Naik 2021). As such, these platforms-and new media as a whole-provide places of freer sexuality, in matters of both degree and diversity.

Another way of looking at popular culture and its location-straddling the heuristic boundaries of mainstream and marginal, mass and high culture-involves studying the linguistic content and references of popular media. The Indian culture industry - not limited to the Hindi or regional film industries-is deeply intertextual, ranging from linguistic and cultural callbacks to the appropriation and transformation of iconic cinematic tropes, moments, and even costumes. There is a tradition of reusing famous lyrics in movie titles, as may be seen in Na Tum Jaano Na Hum [Neither you know nor I] (2002)—a Hrithik Roshan vehicle using a lyric from his debut film—or more recently Ek Ladki Ko Dekha Toh Aisa Laaga [How I felt when I saw that girl] (2019): a queer film borrowing from a heterosexual romantic song featured in 1942: A Love Story (1994). Similar usage has been made of iconic dialogues. There are other borrowings as well, beyond the usage within what may be strictly called Bollywood: with songs from Bollywood films used in the soundtrack of teleserials, or with similar borrowings of iconic costumes. In one sense, these cross-cultural, often cross-medium, references act as deeply idiomatic, mimetic performative utterances that hold the potential to transform meaning even as they reiterate it. Thus, the line "Mogambo khush hua," [Mogambo is pleased] though originally related to the antagonist from Mr. India (1987) has long exceeded this context to signify (earnestly as well as ironically) difficult-to-please people being satisfied; most recently, it was transformed into "phir bhi khush na hua Mogambo" [Mogambo was still not satisfied] in the song "Hanikarak Bapu" [Harmful Dad] in the film Dangal (2016) [Wrestling Match]. A fair segment of the Indian entertainment industry (including but not limited to the Hindi film industry and its subsidiaries) participate and are conversant in what may be called the social dialect ${ }^{6}$ of Bollywood. This cinematic sociolect draws from the semiotic resources of various named-languages (primarily but not exclusively Urdu-Hindi and English) as well as narratival tropes that exceed the media properties where they were first used.

6 A social dialect or sociolect is a "[variety] associated with speakers belonging to a given demographic group" (Biber 1995). 
Examining the use of this mass of intertextuality in and by Agents of Ishq can allow for an exploration of the ways in which the emphasis on Indianness need not signify a conflation of nation and state. The social dialect constituted by and around the Hindi film industry functions as a commonality for an imagined community of Indians. This by no means encompasses all Indians; however, many mainlanders and diaspora (including those not otherwise fluent in Urdu-Hindi as a first language) are conversant in it. Agents of Ishq deploys this familiarity with the dialogues, tropes, and framing of the social dialect of Bollywood in talking about love, sex and romance. We will examine this in greater detail in the following section.

\section{Digital Spaces of Engagement: Agents of Ishq}

Agents of Ishq is a private project, initiated and run by Parodevi Pictures. It is in no way affiliated to or centered around state initiatives for education: the material it produces is not related to state curricula, or broader Indian Ministry of Human Resource Development (in charge of educational policies) guidelines for sex-education. In the traditional sense, therefore, it cannot be called pedagogical. It does, however, produce material that persuades readers into abiding by the norms of sexual behaviour that it idealises and constitutes/reiterates, often using reader responses (to polls, surveys and in response to other posts) to constitute new material.

Agents of Ishq defines itself as a project about "sex, love and desire" in India and among Indians. It has its own website and maintains an active presence on various social media platforms, as well as hosting videos on YouTube. Agents of Ishq recently created an interactive art installation, Love Latika, ${ }^{7}$ in the Goethe Institute in Delhi and Kolkata, using poetry to address questions and illustrate aspects of desire: similar multimedia undertakings are to be found on their website.

Agents of Ishq started out in 2016 through the recognition of a paucity of conversations and conversational spaces about love and desire in India, wherein people felt comfortable talking and asking about acts and experiences that may fall outside the bounds of normative conversation. The project emerged

Because we wanted to create many, many positive conversations about, love, sex and desire. We are often asked to speak about moral policing,

7 Love Latika, described in a trailer as "an electronic forest of erotic poems," uses poetry and songs as well as art of blooming flowers and plants to depict Indian eroticism. 
sexuality, violence. And this is what we have heard in discussions: people want a place to talk about sex and love honestly, without feeling un-cool or ashamed about their confusions [...] we began to wonder - where is the good stuff and the helpful stuff about sex for Indians? Didn't seem to be much. So we decided to make some (AGENTS OF ISHQ, "ABOUT US").

While pointing to a lack of available spaces, Agents of Ishq fails to take into account the various (often long-running) advice columns specialising on love, relationships and sex in various English and vernacular newspapers, weekend supplements and magazines like Manorama, Femina and Sadhana.

In its "About Us" section on the eponymous website, Agents of Ish q declares itself as being against uniformity and conformity.

Actually, we are not into anything uniform. Or telling people what's good, bad, wrong, normal, abnormal, gross, evil. We are not into telling people what to think or feel. At all. There's too much of that going around. Instead, we like to make useful tools, fun materials, things to watch, read and explore so that the world (and particularly young Indians) can make up their own minds.

Following Freire, Agents of Ishq may be said to switch between the banking model-in posts detailing information about safe sex or genitalia, for instance - and the problem-posing method-in posts that pose or answer questions, or analyse the results of previously-conducted polls. It also seeks to interpellate (in the way Althusser and Foucault discuss it) its readers/audience through linguistic and extralinguistic signs, whether through audience-identification in "Love in the Garden of Consent," or by calling its readers 'Agents' (of Ishq) and therefore part of the project.

Agents of Ishq may be considered pedagogical in at least this way: it rarely explicitly instructs or prescribes, but it makes available information which is often conveyed in vocabulary drawn from critical feminist and/or queer theory. It informally promotes what one would call classroom interaction in a formal pedagogic setting, to encourage responses from and discussions with their "Agents" or consumer-participants. Again, one may employ a Foucauldian understanding of the ways in which disciplinary power may act pedagogically, to produce a subject who subjects themself to a normative system, while, simultaneously, acting on themselves to conform to, or otherwise respond to norms. There is indubitably a sense of agency and aspirational proactivity in the term "Agent": one which Agents of Ishq seeks to foster in its audience. 
Further strengthening the argument in favour of regarding it as a pedagogical resource, Agents of Ishq also hosts short presentations and films providing information about sex/gender/sexuality from a queer-feminist and broadly leftist perspective, legitimising it at its root and disallowing perceptions that spring from a conservative perspective. One may look at the illustrated and frankly delightful "What Is Heteronormativity And How Does It Decide What's Normal? An Explainer" for an example of the typical explainers Agents of Ishq provides. (Tabassum 2021) If knowledge rather than ideology is thought of as central to pedagogy, as Das suggests, then pedagogy about sex/gender/sexuality, while driven ideologically is not reducible to any particular ideology, and Agents of Ish $q$ is irrevocably pedagogical.

Agents of Ishq draws on idioms with which the audience is presumed to be familiar, from tropes to commonly-circulated anecdata. It is in this manner that it relies on the social dialect of the Indian entertainment industry, especially that of Bollywood. This reliance extends to an adoption of a hyperreal aesthetic evocative of Bollywood films from the 1970s and early 1980s, an affect that this paper presumes is adopted in order to create an unthreatening and earnest environment to facilitate what may be difficult conversations about sex, sexuality, and socio-sexual health and safety. Thus, in "Hindi Movies Unlocked My Lockdown Libido aka Corona Pyaar Hai Returns ${ }^{8}$, a series of photo-collages taken from various Bollywood films accompanies a screed on the difficulties of romantic and sexual connection in the pandemic and ways to manage and ameliorate the same. Salim and Anarkali from Mughal-e-Azam (1960) [The Great Mughal] ask "when will this lockdown end Jaan-e-Mann??" [sweetheart] (fig 1) while Amitabh Bachchan and Hema Malini smoulder at each other in a collage titled "Door Se Desire ft. Angry Young (Romantic) Man ${ }^{10}$ " [desire from afar] (fig 2) (Babar 2020).

An article called "Sun-Sani Sex-Ed Facts"11" uses posters in a bright, nearly neon aesthetic, with several cutouts of Bollywood characters; the one on age

8 "Pyar hai" translates to "love is"; the phrase "Corona Pyar Hai Returns" therefore translates to "Corona love is returns" or perhaps to "Corona is Love Returns." However, the reference is to the film Kaho Naa... Pyar Hai [Say... It's Love] (200o), using the homophonous resemblance between "kaho naa" and "corona".

9 “Jaan-e-mann" [نان من | जानेमन] is Urdu-Hindi, deriving from Persian.

10 Several of Amitabh Bachchan's roles in the 1970s and 1980s drew upon the "angry young man" trope promulgated by British novelists and playwrights in the 195os. While he was not the only actor to take up such parts, he was both the most prolific and the most popular.

11 While the posters in this series make use of a doodled sun (called, aptly, Sunny) the reference is to the Urdu-Hindi "sansani" [سنسن | सनसनी] which translates to "hair-raising" whether taken as horrifying or scandalous; in this case, most likely the latter. 


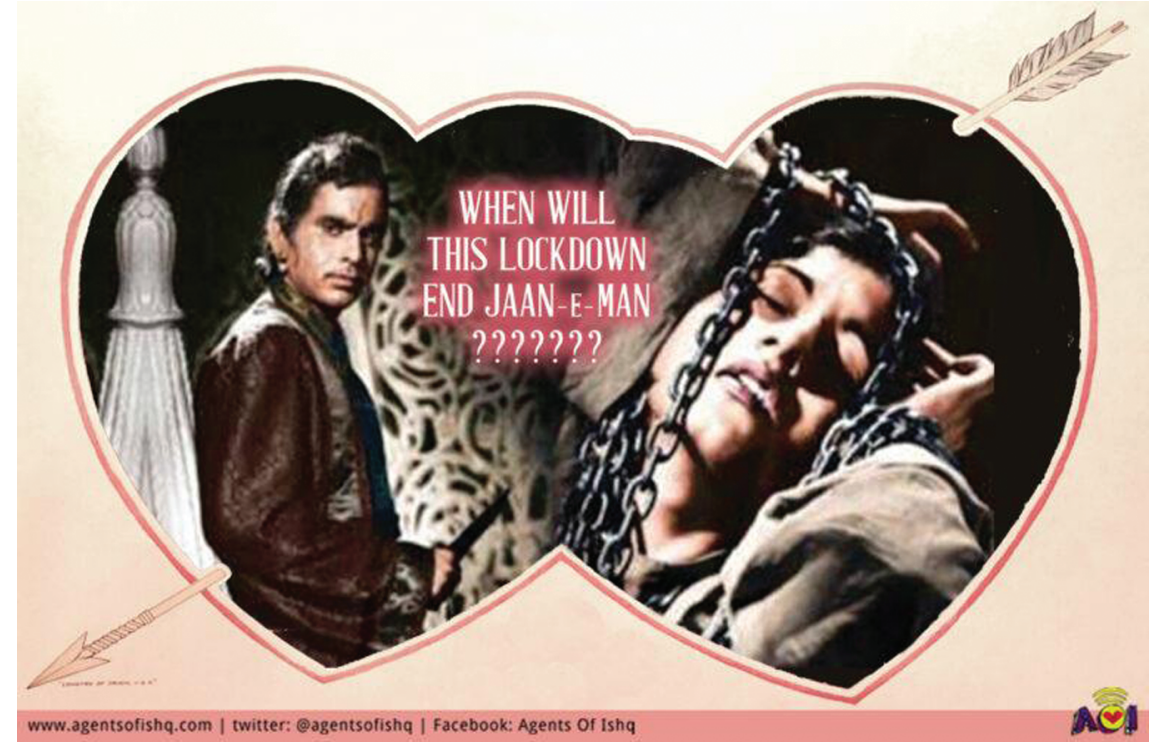

FIGURE 1 When will the lockdown end?

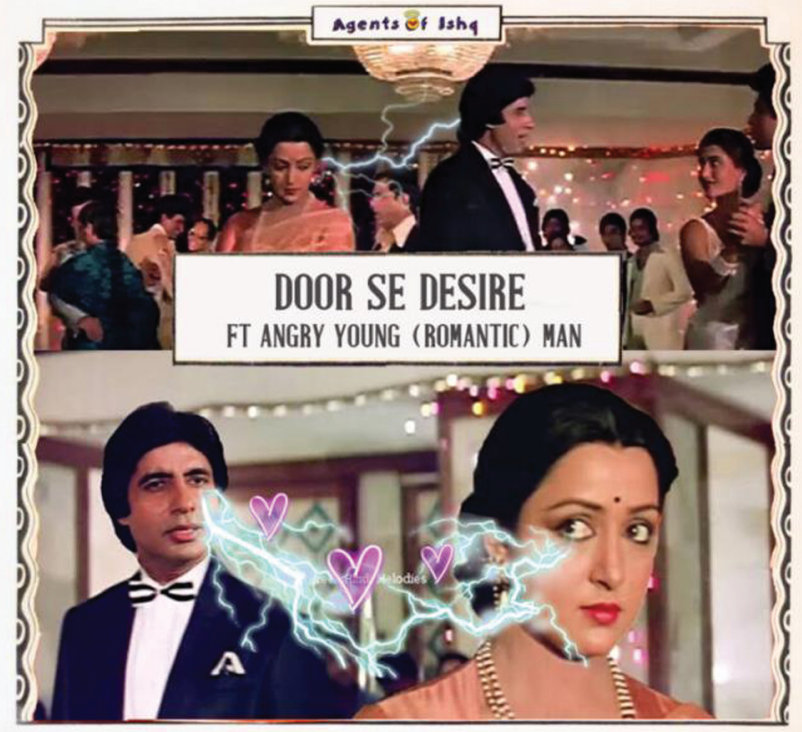

FIGURE 2 Desire from afar 


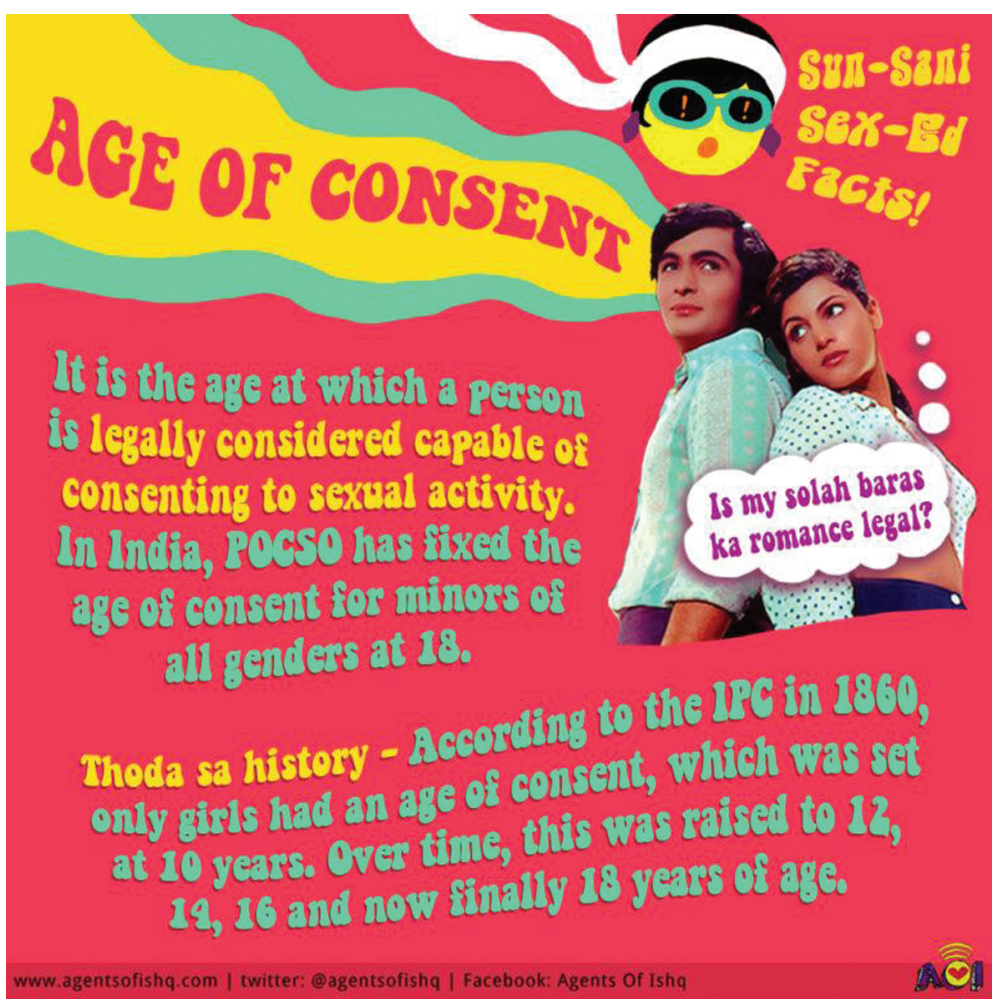

Figure 3 Age of Consent

of consent features the lead pair from teenage romcom Bobby (1973), wondering "Is my solah baras ka romance legal?" [is romancing as a sixteen-year-old legal?] (fig 3).

The article, and this poster in particular, reiterate the retro Bollywood aesthetic triply: by using the leads from a 1970s film, by using the bright colourpalette, and through the doodle of a presumably female head sporting outsized sunglasses and bandana in a very iconic 1970s style. The language of the article which presents "some chatpata sex-ed facts with thoda sa mazaa, dher saara naughtiness, and lots and lots of useful info" [some spicy sex-ed facts with a little bit of fun, a lot of naughtiness, and lots and lots of useful information] further reinforces this impression through recourse to the 'filmi' sociolect (Agents of Ishq 2021). The Bollywood influence extends even to articles that have nothing in common with the plot of the films from which cutouts are sourced: thus,

12 "Chachi" is a Urdu-Hindi word translating roughly to "auntie", but Section 420 of the Indian Penal Code refers to cheating and dishonesty. The title may also refer to Shree 420 (1955) [Mr. 420] but the direct allusion is to Section 420 . The film itself is a remake of the Tamil production Avvai Shanmughi (1996) and ultimately from Mrs. Doubtfire (1993). 
the eponymous character from Chachi $420^{12}$ (1997) shows up in a lab coat talking about the Erogenous Mirror Effect on the Agents of Ishq Instagram account. Agents of Ishq (2020). "agentsofishq", Instagram. 20.12.202O.

This is not, however, to imply that other artistic and cultural influences find no place in Agents of Ishq. For instance, the art installation Love Latika employs Indian poetry and art to explore eroticism; similarly, "How I Taught Myself to Have Orgasms" uses Renaissance and Baroque art while discussing a woman's struggle with anorgasmia (Sen 2017). An episode of the Agents of Ishq podcast, titled "Pyaar toh Hain, Par Sex Nahin" [there is love, but not sex] uses Mughal miniatures, while flowers, fruits, and vegetables take centre-stage in the illustrations of several articles about masturbation as well as in Love Latika (Rudraksh 2017).

Numerous sex-education websites opt for a colourful, pop art affect, probably to indicate easy accessibility, or to evince harmlessness, in effect desexualising sex-education; Agents of Ishq is no exception to this rule, even though its pop art is sometimes sexually explicit. The style is identifiable as pop art but not necessarily homogeneous in aesthetic or style: the website lists three artists, in addition to the illustrations on each post. The pop art on Agents of Ishq's virtual walls is not constricted by style or genre boundaries, but ranges from Jamini Roy-esque figures to retro cutouts to genitalia illustrations evocative of modern queer and feminist art. Together, they reinforce the shared idiom of the website, and work towards achieving the self-evidentiality of its sexual Indianness.

These images are sprinkled through the posts in accordance with the topic at hand, adding another layer of un/intelligibility. It is hard to say if their website holistically draws on a particular school of art, or whether visibly Indian iconography (like Bollywood actors) is arbitrarily assigned to stand-alone projects. Either way, images of Meena Kumari blushing into a telephone, or Kamal Hassan in drag in Chachi 420, are part of the same cultural capital-invested, semantic code that asks for not only a person fluent in various namedlanguages, but also one who is conversant in idiomatic English \& Urdu-Hindi simultaneously in a way that reinforces Bollywood-literacy. A Bollywoodliterate here is someone who not only watches Hindi films, but is aware of a historical movement in and through Hindi films, who knows something about the kind of roles Meena Kumari essayed in her films, and can therefore grasp the juxtaposition of cinematic coyness and the openness with which Agents of Ishq converses about sex/sexuality. This directly aids in, on one hand cementing its imagined community, on the other, drawing out conversations that allow for ambivalences, gaps, incoherences otherwise difficult to access.

On August 14, 2018, Agents of Ishq uploaded a music video titled "Love in the Garden of Consent | Ishq ke Garden Mein Marzi Hai Minimum" to their 
Youtube channel (Vohra 2018). The video description reads "Sexual freedom and romantic joy begin with consent in an ishq-full world of dance and romance!" It was directed by Paromita Vohra, founder of Parodevi Pictures. The cast features faces familiar to anyone who watches various Indian comedy and independent films (also largely hosted on YouTube) and the crew appears in the credits of several of those videos. Tucked in at the very end of the description is a note that contextualises this video as partaking in an ongoing conversation about sex, desire and gender-based violence in India.

Even before one begins watching the video, the double-barred name arrests attention, normal-languaging between English and (transliterated) Urdu-Hindi through local-chaining, ${ }^{13}$ with the English title- "Love in the Garden of Consent" - followed by the Urdu-Hindi title (transliterated in the Roman alphabet): "Ishq ke Garden Mein Marzi Hai Minimum." It employs semiotic resources from the named-languages of English and Urdu-Hindi. Shana Poplack et al (1988) In fact, even the purportedly UrduHindi title incorporates English words: 'garden' and 'minimum'. Further, it provides a colloquial but more nuanced perspective than the English title, which presumes a space of consent whereas the Urdu-Hindi title treats consent as an act. This shift in focus and perspective may serve as an early illustration of normal-languaging employed throughout the various standalone and ongoing projects of Agents of Ishq.

The frame narrative of the video depicts a large group gathered in a grove, with both the place and people decked up in retro Bollywood aesthetics. If one reads this crowd as the audience-insert, then the target audience of the video (which is expected to identify with it) may accordingly be determined as affluent, urban, and liberal-progressive individuals of Indian origin. Everyone is clothed in a mix of Indo-Western outfits widely sold and worn in most Indian urban agglomerations, and use a fluent mix of English and Urdu-Hindi (fig 4). The lead in one of the interspersed stories is attempting to meet work deadlines: at least some of the depicted women may therefore be assumed to work. The speaking subjects of the video-the ones recounting their sexual encounters-are women discussing sex lives with men; however, the crowd in the frame-narrative offers a wider target audience that includes both men and women. The frame-narrative further includes 'gay', 'lesbian' and 'bisexual' as

13 "chaining is conceptualized in terms of emic ways in which human beings connect oral, written and other semiotic resources including different modalities in the course of naturally occurring daily life. It is chaining in and between such resources that creates a communicative flow." Bagga-Gupta and Gynne, 2013: 483. Local-chaining is one of three levels at which chaining has been observed to occur in multimodal scenarios. 


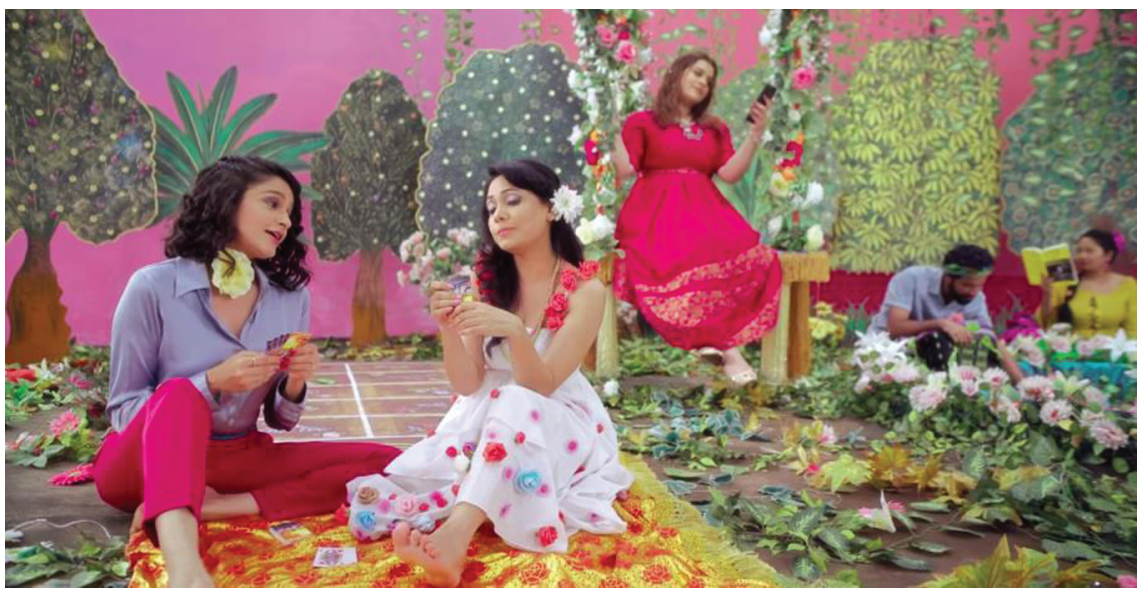

FIGURE 4 Retro Bollywood aesthetics in "Love in the Garden..."

options on a selection of sexual acts, relationships, and orientations, allowing for the possibility that several individuals depicted in that narrative are queer (fig 5).

Interpellation is the process whereby individuals constitute themselves as subjects by acknowledging and responding to ideologies. Ideology has always-already interpellated individuals as subjects, or in a different way, individuals are always-already interpellated by ideology as subjects and thus, "individuals are always-already subjects" (Althusser 1971: 104-105). ${ }^{14}$ Within media studies, interpellation is used to interpret the process by which viewers connect to media texts, whether through a tacit acceptance of the perspective and values of the text — as argued by Adorno and Horkheimer — or in a more agentive manner. Thus, "the interpellation of the individual as subject of its discourse is effected by the identification of the subject with the discursive formation that dominates it." (Pêcheux 1975: 148). Related to interpellation, suturing, exposes the inadequacy of the spectator-subject in order to create a desire for insertion into other cultural discourses which promise to remedy that lack (Oudart 1977). The process of suture allows spectators to constitute

14 Individuals, therefore, are abstract in respect to the subjects that they concretely alwaysalready are. This proposition, Althusser says, might appear paradoxical. However he argues, it is the plain truth that an individual, even before birth, is always-already a subject. He exemplifies this by talking about the unborn child, which before birth is appointed as a subject by and within a specific ideological configuration that expects it, and is therefore always-already a subject since conception. After birth, the subject will have to become the sexual subject it already is, within the constraints of this structured, implacable ideological configuration. 


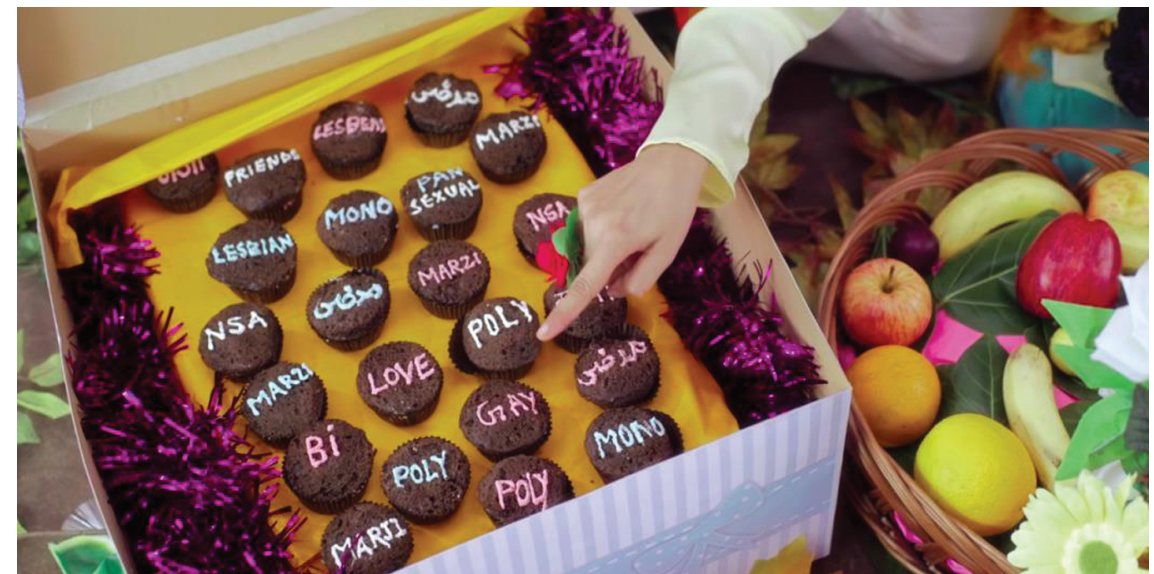

FIGURE 5 Cupcake-box of sexual acts and identities

themselves as the cinematic subject. Suturing is successful when the spectatorsubject identifies with either the stand-in character, or at least with the perspective of the same. Thus,

[t]he absent-one's glance is that of a nobody which becomes (with the reverse shot) the glance of a somebody (a character present on the screen) $[\ldots]$ The reverse shot has 'sutured' the hole opened in the spectator's imaginary relationship with the filmic field by his perception of the absent one (DAYAN 1974: 30).

Interpellation and suturing function through (mis)recognition and (mis) identification, and consequently depend heavily on the on-screen presence of characters with whom the spectator identifies. Thus, media representations are only successful when they have a claim on identity, when the spectator identifies with what is represented in any media production, whether a film, advertisement, or music-video (Hall 1997). This character may be the protagonist or simply have a minor role, but is typically the narrator and often constructed as a reliable one; there may also be a choice of several characters to serve as the audience-insert.

Reverting to the discussion of "Love in the Garden of Consent," the reiteration/evocation of the retro Bollywood aesthetic is evidenced in a hyperreal form, signified through the use of evidently-false flowers and trees and cutouts. If the aesthetic choices typical of commercial Bollywood films in the 197os and 1980s evoke familiarity and safety, then the reiteration of the same choices may be thought of as creating a safe environment in which sex and desire can be 
discussed. Agents of Ishq, importantly, seeks to create a space where sexual and romantic desire may be discussed in an accessible way within familiar spaces: whether locational or discursive. It is also important to reiterate the relative affordability of distributing and hosting new media, especially on platforms like Youtube or Instagram, and that this makes possible the creation of media that might be difficult to place on broadcast media, whether because of its content or the financial capacity of creators or both.

Following this, one may examine the space inhabited by the video, in both the frame narrative and inserted recountings of sexual encounters. The extra-linguistic signs constituting the space-from the cardboard props and silhouettes to the bright neons and deep jewel-tones used-evoke the hyperreal space of the Bollywood song. Storytelling in Bollywood films is often disrupted and heightened by songs, which simultaneously occupy a diegetic and extradiegetic space within the film, disregarding constraints of time and space while adding to the themes of the film. Along with dream sequences-which they often are-songs serve as sites of emotional excess and explicit declarations of romantic (and sexual) intent. The songs are staged as escapes and/or idealised spaces wherein the dreaming/singing characters (typically but not always the leads) can interact with their romantic interests or discuss desired interactions in the company of trusted peers. The video plainly follows this tradition of romantic dramatisation, exceeding its current bounds with the obvious falsity of the props; however, even this is not out of line with the 1970s aesthetic it evokes. While used largely in earnest in films in the 1970s, the usage of these props and/or costumes in 21st century films denotes a certain ironic distance or conscious imitation as may be seen in songs such as "Phir Milenge Chalte Chalte" [We'll Meet Again on this Journey] from Rab ne Bana diJodi (2008) [God Paired Us Off], where the leads interpellate themselves into songs changing in style from the 193os onwards, or the end-sequence of Bombay Talkies, where a song commemorates a century of Hindi films. The use of this style in "Love in the Garden of Consent", while in line with the overall aesthetics of Agents of Ishq, therefore both reiterates and distances it from its Bollywood originals.

Agents of Ishq uses cinematic references to promote a sense of ease, accessibility, and to create a safe space, insofar as safety may mean an ease in communicating otherwise sensitive/taboo/controversial or scandalous confessions or queries. This safety may be located in part in the hyperreality of the space and its evocation of a shared imaginary space in which one expects discourses of romance to be reiterated, if only because of the pervasiveness of mainstream media. This particular reiteration is transformative insofar as it extends the discourse of romance to sexual acts and encounters. Arguably, certain euphemistic and oblique allusions to sex are present in the Bollywood songs this video 
evokes, both through lyricism and cinematography, but "Love in the Garden of Consent" uses the space to further frank and non-euphemistic, if not precisely explicit, conversations about sexual activity. Further, the sexual activity under discussion is not restricted to the marital and would-be marital relations typically depicted and accepted in mainstream media, but includes casual sex and one-night stands, the ethics of which the video discusses without attempts to either condemn or excuse as exceptional.

The "Love in the Garden of Consent" video embeds three accounts of sexual encounters within its frame narrative of conversation about sex: each of these is heralded by a game of hopscotch (seen in the background of Fig 4) with squares labelled with various sexual orientations and motives for sexual activity. The stories are narrated in accordance with the label on the relevant square, a strategy which leaves it to the viewers' imagination whether and what other stories could be narrated by these individuals/characters had they landed on a different square. The uncertainty not only implies a certain fluidity of sexual experience, but also a multiplicity/plurality within the experience of each individual.

Following Derrida (1963), one may say that meaning always holds the possibility of ambivalence, such that it can be interpreted in a way that undoes the statement/perspective/concept it appears to affirm in a different interpretation. This video is ambiguous, insofar as the ways in which it aspires to being accessible and helpful in creating a particular perception about consent, work to create an inimical interpretation.

"Love in the Garden of Consent" sets up a trifecta of ways to engage in sexual activity — tann [body], mann, which is glossed as [heart] in the subtitles, and fun-which is reiterated at several points during the remainder of the song. This discussion of sex as enacted for fun, and for lust, alongside emotional engagement, marks progress from mainstream-media depictions of sex as a part of a serious relationship, often marital or would-be marital. This may be read as forming a contrast to social reactions to casual sexual encounters, which are not typically accepting of women engaging in such acts.

The video succeeds in depicting the way in which three differently-marked intentions can characterise any sexual act: serious commitment, hookups, and lust. However, it is less successful in talking about sex-an embodied practice- to determine the distinctions between mind-in-body, a separation of mind and body and the primacy of body over mind. ${ }^{15}$ In an environment rife

15 This video was screened at a reading group of students from Ms University, Vadodara, and an earlier version of this paper was presented at a media studies conference in K.C College, Mumbai. About half the audience at both found the use of these distinctions discomfiting; several pointing to their use in sexual assault discourses, with men framed as being unable to conquer bodily instincts. 
with discomfort about sex and sexuality, trying to distinguish between these three categories harms the destigmatisation the video aims at, especially insofar as it posts women as sexually-agentive, as seeking sex. While the 'fun' label appears to be an unproblematic description of casual sex, the viewer has to glean this contextually from the video: there are no explicit definitions offered. This too leaves open certain ambiguities, not least about the gendered nature of this 'fun' since common public discourse about sexual assault involves assumptions about masculine enjoyment in the act. Terms like 'jaanemann' [lover], 'saiyan' [lover] etc, are also ambiguous, as they refer to romantic partners and, while usually read in a deeply monogamous vein, are by no means exclusionary of more casual partnerships.

One may construct the use of these terms, this ambiguous language as deliberate in this conflation, expecting similar amounts of care from both Mr. Right and Mr. Right Now, but it has the effect of also creating a romantic environment where none might exist. The lack of boundaries-perhaps in place as an inclusive gesture-similarly creates a somewhat anxious space around terms like 'ranj' 'manj' and 'tanz', which are Urdu-Hindi terms relating to romantic pining and teasing, and may not be semantically accessible to all viewers. It is perhaps inevitable that a video that employs Bollywood tropes would carry over the ambiguities around sexual interactions that characterise the movies.

A question of access is perhaps timely in any case. One must take into consideration both the ease with which Agents of Ishq may be accessed and who is most likely to find it accessible. The basic conditions of accessing Agents of Ishq's work are not too difficult: an internet-enabled device, preferably a private profile - if not a private device — as the material is often explicit in its discussion and sometimes illustrations of sexual organs and practices. Perhaps as crucially, one must be either comfortable enough with social media to discover their handles on Twitter or Facebook, or inhabit the feminist and queer social circles which include those who can perform an introduction. The material requires fluency in idiomatic English and idiomatic Urdu-Hindi, which is peppered into the posts on the putatively-English version of the site, in accordance with their overall aesthetic and vocabulary. Interestingly, the Urdu-Hindi vocabulary is transcribed in the Roman alphabet; the Hindi version of the site (which is more sparse) uses Devanagri script. Less quantifiable, but at least as important, is the extent to which one is compliant with Indian cultural norms regarding sex/gender/ sexuality: a certain resistance or at least curiosity is needed to seek out and like Agents of Ishq and similar sites. Technically, the site is free and easy to access: it is neither invite-only, nor behind a paywall. However, without the 
aforementioned linguistic, technological and cultural awareness, it remains unintelligible. Even if one uses a Foucauldian reading of pedagogy as an aspect of productive power insofar as it assists a subject in subjectivating themselves, Agents of Ishq falls short, since it is only intelligible to those who have already undergone the process. It is not attempting grassroots outreach, which is in any case illegal in many Indian states insofar as sex-education for underage citizens is concerned.

Despite this, one cannot discount the website as addressing only an in-group that is already in the know. In discussing any other topic, the website - with its conditions for intelligibility - would be fairly insular. However, in matters of sex/gender/sexuality, the moment one expands even to the acknowledgement of heteronormativity as a norm rather than as the normal, one has expanded beyond the in-crowd. Thus, "Why Men Don't Talk About Masturbators-and Other Questions You Never Thought To Ask" is by a disabled man talking about desire and the disabled male body: a topic which is not usually addressed as part of masculine desire in India (Anicca 2021). Anicca finds that the availability of this sexual technology in the Indian market has not translated to the concept's availability in Indian discourse about sex. Able-bodied people don't have a window into the emotional and sexual lives of the disabled, just as even self-identified liberal and progressive heterosexual people don't have a window into the emotional and sexual world of queer people, often including their friends. Further, Agents of Ishq runs an advice column, tagged "Small Doubts," which opens up the conversation with people who require that advice in a way unlike those habitually perusing or contributing to the website. This advice column comes in addition to the already available options for people to discuss their own sexual encounters or desire, and the explicit $\mathrm{Q} / \mathrm{A}$ format allows for more tentative and unpracticed voices to be both heard and addressed. Specific concerns filter in through this column: concerns the Agents of Ish q content-developers may not otherwise address, if only because they may not conceptualise these as doubts/questions that need answering. It is difficult to be comprehensive in matters of sex/gender/sexuality, where an element of unpredictability lingers: information offered will always leave more scope for related, or different questions.

Despite its esotericism and arguably elitism, the website opens up windows into a hundred people's bedrooms, and even better, into their thoughts about sex: invaluable in a sex-ed starved country like India. Agents of Ishq's attention to intersectional subjectivity allows for a social conversation on sex/gender/ sexualities despite the lack of the pedagogical tonality that characterises targeted informational campaigns about AIDS or safe-sex. 


\section{Discursive Constructions and Decolonizing Digital Pedagogies- Issues and Challenges}

Agents of Ishq is pedagogic insofar as it participates-and persuades its readers/audience to participate-in a system of governmentality bigger than itself, including but not limited to the state, while taking into account medico-legal norms, social conventions, and to some extent, the intersectional contingencies of its potential or present user-base.

Further, it is itself governmental, insofar as it frees through the act of subjecting, and is a site of both resistance and containment. It pushes the boundaries of publicly-possible sexually-explicit conversations and the public dissemination of sexual information to disabuse readers of the myths, falsehoods, and fallacious conjectures around sex. Simultaneously, it draws from a whole body of medico-juridical institutional information in an act of conforming solidarity.

The discussion of Agents of Ishq as a site of popular culture is not limited to its self-presentation as a platform conversant with the Indian, Bollywoodcentric sociolect. The performativity of its posts relies on the way it challenges norms of discretion, but simultaneously, draws on and engages with institutional knowledge. It acts as a mediator between its readers and social institutions vested with medical, legal, academic knowledge of sex/gender/sexuality. Reading it in terms of governmentality frees us from reducing it to terms of purely hegemonic or counter-hegemonic ideology. This flexibility is crucial, because unless we acknowledge this intermediary nature of Agents of Ishq, in terms of both its structural role and action we cannot critique the blind spot it creates in the process.

As previously mentioned, the material hosted on the Agents of Ishq website is not designed to be included in school curricula, ${ }^{16}$ though there are contact details provided in case anyone wishes to use the material in their own work. This lack of systematic use in a formal setting need not necessarily detract from the site's utility as a pedagogical resource. Yet there is a certain temptation to assume that Agents of Ishq is only in conversation with those already in the know, in part because of what emerges as its user profile (see analysis in section $\mathrm{x}$ ). In addition to the website, Agents of Ishq maintains a social media presence, and is consistently active on Twitter; despite this, their outreach and engagement numbers are not very high. If one takes the video analysed as an example, it has accrued 21,358 views, with 423 likes, 13 dislikes, and a relatively short and startlingly positive thread of 20 comments despite a lack

16 The Agents of Ishq offices are located in Mumbai, the capital of Maharashtra, which is one of several Indian states to have banned sex-education in schools. 
of comment moderation since being posted on 14 August, 2018 (fig 6). Unlike Agents of Ishq, YouTube records lesser engagement: this is important because in matters of sex/gender/sexuality, passive engagement is likely to be higher than active interaction, even pseudonymous or anonymous.

Agents of Ishq tries to create a third-space/middle-space of sexually-open conversation that is neither pornographic nor entirely evoked by the commercial films of Bollywood; while it is not the first to do so, the effort is still remarkable. Despite the existence of sex-advice columns in news media and of depictions of sex in parallel and increasingly commercial cinema, the space afforded to public, non-judgemental discourse about sex and sexuality in India is still rather small. Agents of Ishq draws from the available body of conventional knowledge, to offer a range of non/normative actions which it in the process normalises. This translates into the fact that whoever is hopeful or afraid or even knowledgeable about sex, can draw affirmation or awareness from the site. Queries and posts on Agents of Ishq make it clear that even individuals who identify as liberal-progressive and sexually liberated may be unaware of the wide spectrum of concerns that lie between the putative polarisations of a sexually-liberated 'Western' outlook and a constrictive, dogmatic 'Indian' or 'Eastern' one. The website tries to resist these homogenisations in favour of the

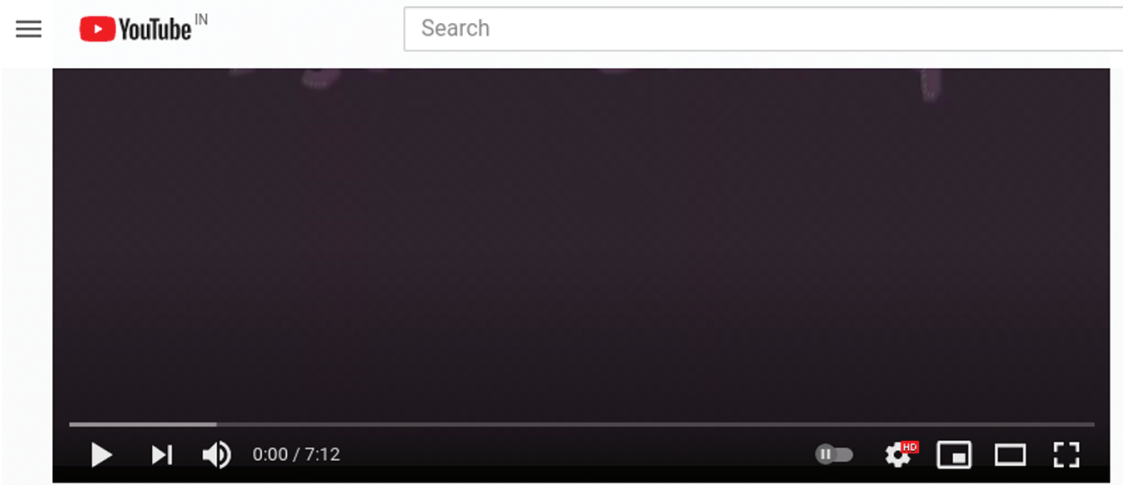

Love in the Garden of Consent / Ishq ke Garden Mein Marzi Hai Minimum 21,358 views - Aug 14,2018 If 423 q $13 \rightarrow$ SHARE $\equiv+$ SAVE $\ldots$

Sexual freedom and romantic joy begin with consent in an ishq-full world of dance and romance!

Directed by - Paromita Vohra

FIGURE 6 Love in the Garden of Consent: views, likes, dislikes. 
heterogeneities and intersectionalities within which modern Indian (sexually active or curious) identities are imagined.

Even if we try to foreground intersectionality in contemporary queerfeminist discourses, we are always aware of the way in which the experience of no two people is exactly alike, even if they are a perfect match in all demographic details. Despite this, such identity labels or subject positions presume some commonality in shared experiences, and that creates a point of community solidarity. However, that also creates an increased awareness of the interiority of an experience. No matter how familiar or tired such identity labels may appear, they ask for a reintegration and reinvention in any identity project. Every member participating in the shared commonality may receive some information about how their social realities overlap, but also have to experience it for themself, in their own unique way. Identity projects are built through individual contingent accounts that account for difference even as they foreground similarities. One has to always learn about oneself, and then has to, simplistically speaking, go and look for other people who have also learnt/experienced the same truth about themselves. This applies to all identity groups, though one may not need to look further than immediate family for several.

Sex/gender/sexuality, however, work in a mind-body duality that asks for a distinct moment of awareness or discovery, irrespective of one's other dis/ privileges: even able-bodied cisheterosexual men undergo this moment of discovery, generally at puberty. Through the tempering of norms and personal predispositions, one acquires the knowledge of one's sexual workings, preferences, and (eventually, hopefully) the etiquette of how to approach these matters. These are not predetermined biological universalities, and render all matters of sex/gender/sexuality to some extent an unmapped territory that must be individually explored. Even as we explore the ways in which Agents of Ishq's different interactive representations aspire to create an imagined community, we need to be aware of how this community may instead appear like a crowd of individuals, not least because their commonalities may not be apparent.

\section{Concluding Remarks}

In the beginning of this piece, we mentioned Mignolo's commentary on how he thinks knowledge systems are hierarchised. For Mignolo, this hierarchization happens primarily in terms of the Global North and the Global South. Mignolo speaks from within a decolonial framework that seeks to 
problematise an Eurocentric understanding of modernity in which in most societies Global North and Global north-based knowledge systems are considered more prestigious, universal and comprehensive. These systems often occlude (and deem inferior) localised, non-Eurocentric modernities experienced across locations other than Europe, in ways not derivative of the European model of modernity. When it comes to feminisms, queer studies and other contemporary discourses of embodiment, there is a tendency to assume these as primarily imported from a ubiquitous West: we can see this, for instance, in the way sex-education is perceived by different political lobbies in India. Decoloniality is an exercise of unentangling the proliferation of modern knowledge systems in ways that destabilise the hegemony of the Eurocentric episteme, and the insularity of the Global north/Global South binary polarisation in favour of porosity.

This paper has read Agents of Ishq primarily in light of how its performativity - through a process of reiteration and transformation of familiar linguistic and cultural tropes-brings into being an imagined community to which it caters. The hybrid modernity of Agents of Ishq is not accessed through top-down frameworks of knowledge production and dispersion, but rather through that of decoloniality. The content and community constituted by Agents of Ishq incorporates global ideas and local identities, discussing commonalities without generalising or essentialising questions of sex and desire. Its deliberate use of the Bollywood sociolect provides a key to its attempt to construct an imagined community of desirous Indians that incorporates differences without homogenisation, and resonates with local popular culture instead of borrowing from the Global North. This does not, however, mean it is incapable of acts of epistemic violence; the cultural hegemony of Bollywood productions in India is not without complications, and the use of its aesthetics implicates Agents of Ishq. That is all the more reason for it to be examined within these frameworks, if only to see what peculiar, particular configurations they produce.

A project like Agents of Ishq would have been of interest in any country: one may think of Scarleteen, which is in some way its American counterpart. In a country like India it is doubly so, imparting information about sex/gender/ sexuality not necessarily solely to adolescents but adults kept ignorant through the workings of a repressive state and conservative society. More projects and content of this kind is sorely needed in Indian public discourse about sex/ gender/sexuality. However, it is simultaneously crucial to critically read the identifying practices, norms and aspirational processes of meaning-making on which such content relies. 


\section{References}

Adorno, Theodor and Max Horkheimer. "The Culture Industry: Enlightenment as Mass Deception." Dialectic of Enlightenment. Amsterdam: Querido Verlag.

Agents of Ishq (2020). "agentsofishq", Instagram. December 20, 2020. URL: https:// www.instagram.com/p/CJAjUDsJ64Z/ (Accessed on April 16, 2021).

Agents of Ishq (2021). “Sun-Sani Sex Ed Facts!” Agents of Ishq. April 2, 2021. URL: http:// agentsofishq.com/sun-sani-sex-ed-facts/.

Althusser, Louis (1971). "Ideology and Ideological State Apparatuses". In Lenin and Philosophy and other Essays (Translated by Ben Brewster). New York: Monthly Review Press.

Anicca, Abhishek (2021). "Why Men Don't Talk About Masturbators - and Other Questions You Never Thought To Ask." Agents of Ishq. March 4, 2021. URL: http:// agentsofishq.com/men-and-masturbators/.

Babar, Aneela Zeb. "Hindi Movies Unlocked My Lockdown Libido aka Corona Pyaar Hai Returns". Agents of Ishq. July 20, 2020. URL: http://agentsofishq.com/ lockdown-libido/.

Bagga-Gupta, Sangeeta and Annaliina Gynne (2013). "Young People's Languaging and Social Positioning. Chaining in "bilingual" Educational Settings in Sweden." Linguistics and Education. Vol. 24, Issue 4. (December 2013): 479-496.

Bahukhandi, Shivani (2017) "No Sex Until Marriage! The Hypocrisy Around Premarital Sex". Feminism in India. 31 August 2017.

в вС (2021) "India is now only 'partly free' under Modi, says report”. BBC News. 3 April 12, 2021. URL: https://www.bbc.com/news/world-asia-india-56249596.

Biber, Douglas. Dimensions of Register Variation: A Cross-Linguistic Comparison. 1995. Cambridge: Cambridge University Press.

Chandani, Priyanka (2020). "Pornographic websites may be banned in India, but consumption of porn has only spiked." Deccan Chronicle. August 30, 2020.

Chris, Barker. (2004) SAGE Dictionary of Cultural Studies.

Das, Dilip K. (2019). Teaching AIDS: The Cultural Politics of HIV Disease in India. Singapore: Springer.

Dayan, Daniel (1974). “The Tutor Code of Classical Cinema." Film Quarterly Vol. 28, No. 1 (Autumn, 1974): 22-31.

Derrida, Jacques. (1963) "Force and Signification." anthologised in Writing and Difference (1978) trans. Alan Bass. Chicago: University of Chicago Press.

Freire, Paulo. Pedagogy of the Oppressed (trans: Ramos, M. R.). London: Penguin.

Foucault, Michel (1972). The Archeology of Knowledge. London/New York: Routledge.

Foucault, Michel (1977). Discipline and Punish: The Birth of the Prison. London: Penguin.

Foucault, Michel (1978). The history of Sexuality Volume 1: An Introduction. London: Penguin. 
Foucault, Michel (1980). "Body/Power" and "Truth and Power". In Michel Foucault: Power/Knowledge: Selected interviews and other writings 1972-1977. New York: Pantheon Books.

Foucault, Michel (2000). Power (trans: Hurley, R., et al.) (Ed: Faubion, J.). New York: New Press.

Foucault, Michel (2007). Security, territory, population: Lectures at the Collège de France 1977-1978 (trans: Burchell, G.). New York: Palgrave Macmillan.

Freire, Paulo (1994). Pedagogy of hope: Reliving Pedagogy of the Oppressed. London/ New York: Continuum.

Hall, Stuart (1981). "Notes on Deconstructing the Popular." In People's History and Socialist Theory. Edited by Raphael Samuel. New York: Routledge.

Hall, Stuart (1997). "The Work of Representation." In Representation: Cultural Representations and Signifying Practices. Edited by Stuart Hall. London: Sage Publications.

Krishna, Dhruv (2020). "Sex education: Still a taboo in India?” Times of India. July 15, 2020.

Liang, Lawrence (2011). "Is it a bird? A plane? No It's a Magic Chair!" E-Flux. Journal \# 27. September 2011. URL: https://www.e-flux.com/journal/27/67979/ is-it-a-bird-a-plane-no-it-s-a-magic-chair/.

Louise, Nick (2020). "These 6 corporations control 90\% of the media outlets in America. The illusion of choice and objectivity." Tech Startups. September 18.

Mignolo, Walter (2019). "Epistemic Reconstitution(s), Colonial/Imperial Difference and Border Thinking." Balvant Parekh Distinguished Lecture, 2019. Baroda, India.

Naik, Amit Raja (2021). "As отт Platforms Formalise Self-Regulation Code, India Brings Censorship One Step Closer." Inc42. February 11, 2021.

Oudart, J. P. (1977). Dossier suture: Cinema and suture. Screen, 18(4), p. 35-47.

Pêcheux, Michel (1975). Les Vérités de La Palice. Paris: François Maspero.

Poplack, Shana, David Sankoff and Christopher Miller (1988). "The Social Correlates and Linguistic Processes of Lexical Borrowing and Assimilation". Linguistics 26 (1988): 47-104.

Rudraksh. "Pyaar Toh Hai, Par Sex Nahin." Agents of Ishq. May 19, 2017. Podcast URL: http://agentsofishq.com/pyaar-toh-hai-par-sex-nahin/.

Sen, Anushka Radha (2017). "How I Taught Myself To Have Orgasms". Agents of Ishq. June 19, 2017. URL: http://agentsofishq.com/how-my-orgasm/.

Tabassum, Rukhsana (2021). "What Is Heteronormativity And How Does It Decide What's Normal? An Explainer." Agents of Ishq. March 7, 2021. URL: http:// agentsofishq.com/what-is-heteronormativity-a-comic/. 
Vohra, Paromita (2019). “A Love Latika - Trailer”. Parodevi Pictures. YouTube. Accessed April 12, 2021. URL: https://www.youtube.com/watch?v=FSGFCoOilio.

Vohra, Paromita (2018). "Love in the Garden of Consent/Ishq ke Garden Mein Marzi Hai Minimum”. Agents of Ishq. August 14, 2018. Youtube URL: https://www.youtube. com/watch?v=cY_F5RO-wps. 